\section{Industrial Noise as a Source of Threat in the Field of Blasting Technology in Coal Mines}

\author{
Piotr Mocek \\ Silesian University of Technology, Poland
}

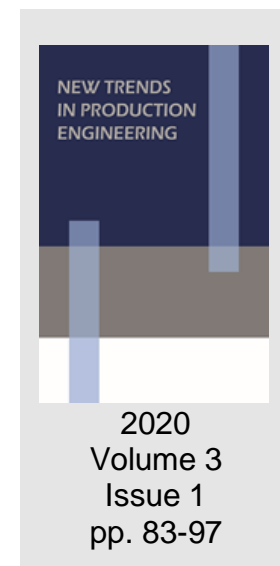

Date of submission to the Editor: 02/2020

Date of acceptance by the Editor: 03/2020

\title{
INTRODUCTION
}

According to the report of the European Agency for Safety and Health at Work noise-induced hearing damage is the most common occupational disease in Europe because it accounts for around one third of all work-related diseases and is more common than skin and respiratory diseases. Millions of employees in Europe are exposed to noise at work and all risks associated with it. About $7 \%$ of them suffer from hearing problems (Eurostat, 2014). Hearing loss due to noise is one of the most recognized occupational diseases in the EU (EU OSHA, 2012), and hearing loss is no longer a problem only in industries such as heavy industry, construction and mining. It also appears in other sectors of the economy.

Due to the fact that in industrial conditions communication and hearing process are disturbed by noise, the probability of accidents increases in those places where noise is the highest. Even relatively low noise levels can cause problems in the workplace because the noise is annoying and disturbing. Noise can cause stress reactions that have a detrimental effect on the ability to concentrate and on productive efficiency (Koradecka D., 2010).

The research of the Institute of Occupational Medicine in Łódź shows that as a result of many years of exposure to noise exceeding $85 \mathrm{~dB}$ in industrial conditions, workers receive symmetrical hearing loss, particularly in the high frequencies, especially in the range of $3-6 \mathrm{kHz}$, which in the early period of hearing damage may remain unnoticed by an employee. The main reason for this is that the first changes to sound reception problems relate to frequencies higher than the speech band. The dynamics of hearing damage caused by industrial noise is relatively fast during the first 10 years of exposure, after which it slows down. After 15 years of work in abnormal noise, the first cases of hearing damage involving lower frequencies, i.e. $<2 \mathrm{kHz}$, are already recognized. In turn, 30 years of exposure to noise can cause total deafness (IMP, 2020). 
The number of people exposed to noise in the work environment represents a significant percentage of employees in various branches of the economy. One of the sectors mentioned above is mining, which is one of the 'noisy' industries with significant noise emissions. The specificity of this industry are among others, high-power machines and devices that produce noise at very high levels. Currently used mining technologies, the use of explosives, loading and transporting spoil, often constitute sources of excessive noise and cause a significant acoustic hazard. It also happens that hearing loss occurs as a result of one-off contact with strong noise, e.g. during blasting operations in mining excavations.

Persons performing work in positions directly related to the extraction and primary processing of raw materials are constantly exposed to its harmful effects. This is often a low-frequency noise, particularly difficult to suppress, for which collective and individual protection measures are of low efficiency.

The report of the Higher Mining Office of the WUG regarding the assessment of the state of work safety, mining rescue and universal safety in connection with mining and geological activity (WUG, 2019) shows that in the years 2012-2018 in mining in total 2829 cases of occupational diseases were found, of which the most of pneumoconiosis (2041 cases), which accounts for $84.9 \%$ of all occupational disease cases diagnosed at that time. Occupational hearing damage is second in this statistic in both mining generally and in hard coal mining (Table 1 and Table 2).

Table 1 Structure of incidence for individual units sickness in total mining in the years 2012-2018

\begin{tabular}{|l|c|c|c|c|c|c|c|c|}
\hline \multicolumn{1}{|c|}{ Illness } & $\mathbf{2 0 1 2}$ & $\mathbf{2 0 1 3}$ & $\mathbf{2 0 1 4}$ & $\mathbf{2 0 1 5}$ & $\mathbf{2 0 1 6}$ & $\mathbf{2 0 1 7}$ & $\mathbf{2 0 1 8}$ & Total \\
\hline Pneumoconiosis & 386 & 408 & 425 & 277 & 439 & 251 & 215 & 2401 \\
\hline Permanent hearing loss & 36 & 24 & 36 & 23 & 27 & 23 & 23 & 192 \\
\hline Vibration white finger & 43 & 21 & 17 & 5 & 6 & 4 & 3 & 99 \\
\hline Chronic diseases bronchitis & 4 & 3 & 3 & 3 & 2 & 1 & 1 & 17 \\
\hline Other occupational diseases & 33 & 16 & 18 & 18 & 14 & 9 & 12 & 120 \\
\hline Total & $\mathbf{5 0 2}$ & $\mathbf{4 7 2}$ & $\mathbf{4 9 9}$ & $\mathbf{3 2 6}$ & $\mathbf{4 8 8}$ & $\mathbf{2 8 8}$ & $\mathbf{2 5 4}$ & 2829 \\
\hline
\end{tabular}

Source: (Higher Mining Office, 2019, www.wug.gov.pl)

Table 2 Incidence structure for individual units diseases found in hard coal mining in 2012-2018

\begin{tabular}{|l|c|c|c|c|c|c|c|c|}
\hline \multicolumn{1}{|c|}{ Kind of illness } & $\mathbf{2 0 1 2}$ & $\mathbf{2 0 1 3}$ & $\mathbf{2 0 1 4}$ & $\mathbf{2 0 1 5}$ & $\mathbf{2 0 1 6}$ & $\mathbf{2 0 1 7}$ & $\mathbf{2 0 1 8}$ & Total \\
\hline Pneumoconiosis & 359 & 356 & 394 & 234 & 393 & 203 & 158 & 2097 \\
\hline Permanent hearing loss & 32 & 19 & 26 & 15 & 20 & 13 & 14 & 139 \\
\hline Vibration white finger & 42 & 18 & 16 & 5 & 6 & 1 & 2 & 90 \\
\hline Chronic diseases bronchitis & 4 & 2 & 3 & 3 & 2 & 1 & 1 & 16 \\
\hline Other occupational diseases & 26 & 12 & 14 & 15 & 13 & 6 & 7 & 93 \\
\hline Total & $\mathbf{4 6 3}$ & $\mathbf{4 0 7}$ & $\mathbf{4 5 3}$ & $\mathbf{2 7 2}$ & $\mathbf{4 3 4}$ & $\mathbf{2 2 4}$ & $\mathbf{1 8 2}$ & 2435 \\
\hline
\end{tabular}

Source: (Higher Mining Office, 2019, www.wug.gov.pl) 
Analyzing the above data, it should be remembered that two significant conditions have a decisive impact on the number of occupational diseases diagnosed in mining.

1. the period during which the symptoms of the disease can be documented. For pneumoconiosis, the list of occupational diseases does not specify the time during which symptoms of this disease must be documented, despite early termination of work exposure. This means that the numbers of pneumoconiosis cases in 2018 presented in Tables 1 and 2. also includes employees who ended their work in occupational exposure even 20 years or more ago, as well as those who ended their work in mines liquidated even earlier. Meanwhile, in the case of permanent hearing loss, the time to document the symptoms of an occupational disease is, according to the list of occupational diseases, only 2 years.

2. the fact that $85 \%$ all identified cases of occupational disease in mining are reported by employees only after retirement.

Due to the above, in 2019, as part of scientific research, a hearing test was screened among miners of hard coal mines with the participation of the Mobile Hearing Research Center, which was to determine the scale of hearing disorders among employees of hard coal mines and to select the sections at the mines and plants with the highest risk noise. One of such departments at hard coal mines, as research has shown, is the Department of Blasting Technology. The publication presents the scale of this threat and its causes.

\section{HEARING TEST METHODS AND SYSTEMS}

Hearing test - it is a process consisting in assessing the body's response resulting from sound stimulation, aimed at determining the degree of hearing impairment or its exclusion in a tested person preceded by a preliminary ear examination.

1. Otoscopy - ear speculum - is a physical examination of the ear with the help of an ear speculum that is inserted into the ear canal. In this test, the external auditory canal is assessed (Fig. 1) and indirectly the middle ear by assessment of the tympanic membrane.
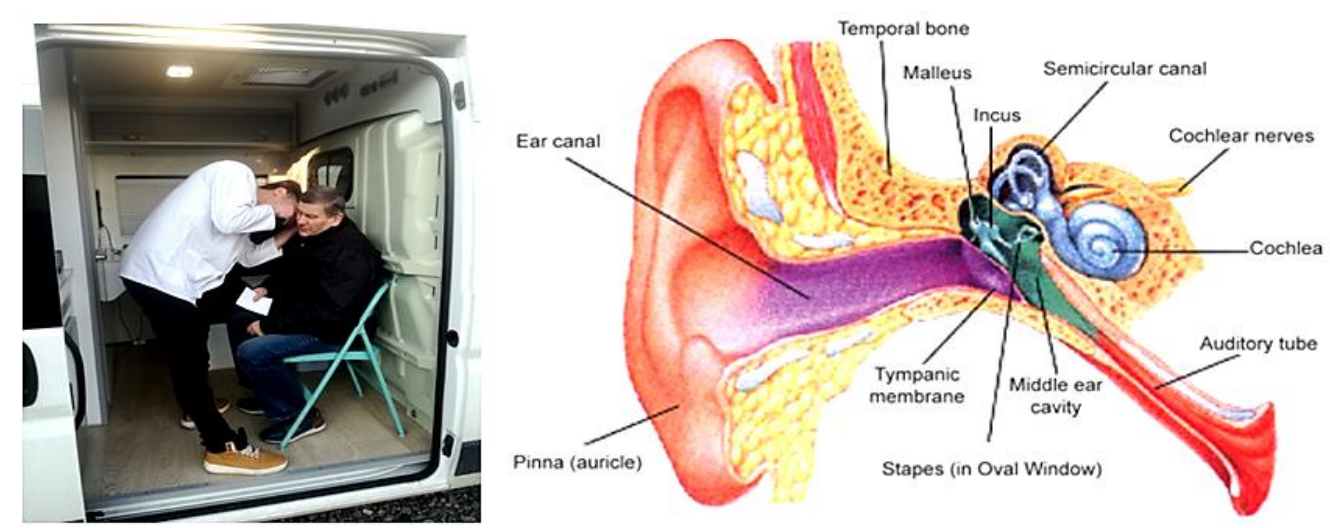

Fig. 1 Otoscopy - viewfinder hearing test 
This test can also be performed using the Siegle sight glass, in which the tympanic membrane is enlarged, and the mobility is assessed by increasing the air pressure in the duct using a balloon located near the sight glass.

An ear microscope is also sometimes used for physical examination of the ear, which is also used in ear microsurgery. To assess the condition of the middle ear, apart from the mentioned tests, it is necessary to test the patency of the eustachian tube. Its patency is assessed using so-called Valsalva tests (SH Lim, Jan 1998), in which the subject blows air out of the lungs into the nose with his mouth closed and the wings of the nose pinched. The second attempt by the doctor to check the patency of the eustachian tube is the so-called Politzer test (R Nagappan, Jun 2002). It consists of injecting air into the nasal cavity and nasopharynx using a balloon with a cap. The murmur of air passing through the eustachian tube is heard through a so-called listener, i.e. a rubber hoses whose attachments are placed in the ear canal of the examined person and the doctor. In addition to physical examinations, the functional state of hearing and balance should also be assessed for ear condition.

\section{HEARING TEST (AUDIOLOGICAL TESTS)}

Hearing test can be:

a) Subjective examination consisting in confirmation by the patient of hearing individual sounds given by the investigator.

Audiometric tests - this is a qualitative and quantitative assessment of hearing. The simplest subjective test evaluates hearing by colloquial speech, whispering and reeds using three tests:

- binaural bone conduction - Weber's test (Kozubski W. 2002), in which hearing symmetries are assessed,

- for monaural bone conduction - Schwabach test, which compares the bone conduction of the examined person and the researcher assuming the correct hearing in the researcher,

- air conduction - Rinneg's test (P. Leffers, 1989), which compares the audibility of the reed by air and bone.

In the audiological laboratory, subjective hearing testing is:

- tonal threshold audiometry - involves measuring with air or bone conduction, hearing loss for sinusoidal tones with different frequencies. The results are presented in the form of curves - audiograms that show the hearing threshold. The hearing threshold is determined by gradually amplifying the tone - the ascending method, or by weakening it - the descending method. The frequency band at which the smallest value of audible tone allows to determine the hearing threshold remains in the range from $250 \mathrm{~Hz}$ to $8 \mathrm{kHz}$,

- high frequency audiometry - consisting in determining the hearing threshold at high frequencies: from $8000 \mathrm{~Hz}$ to $20,000 \mathrm{~Hz}$, this is a clinical trial requiring an audiometer with an extended frequency scale; this test is used to detect early defects caused by exposure to noise, or due to aging of the hearing organ, as defect in high frequencies is the first symptom of these ailments, 
- verbal audiometry and threshold tests - is a test that is used to assess social hearing performance, i.e. the ability to communicate in everyday life. In other words, it is a study that shows whether the respondent understands the words spoken (Śliwińska-Kowalska, 2005).

b) An objective test - independent of the patient's will - consisting in recording electrical potentials in the nervous system (brainstem and cortex) arising under the influence of acoustic stimuli.

Objective research includes:

1. impedance audiometry - based on the measurement of staple muscle reflexes and tympanic membrane tension (Śliwińska-Kowalska, 2005),

- typanometry - involves measuring the reflection of the sound wave from the tympanic membrane when the pressure in the external auditory canal changes. Its result is the formation of a curve, tympanogram, with which you can diagnose, among others eardrum rupture, middle ear infections, eustachian tube obstruction and abnormal retinal reflex disappearance.

- Stapes muscle reflex - consists in causing a protective reflex against the given sounds of too high intensity, which causes contraction of the intraear muscles and stiffening of the ankle chain, which weakens the stimulus by approx. $10 \mathrm{~dB}$. The basic frequencies for triggering a reflex are: 500, 1000, 2000, $4000 \mathrm{~Hz}$.

- test for the disappearance of the stapes muscle reflex,

2. Otoacoustic Emission - It involves the inner ear emitting sounds in response to an acoustic stimulus (crackling) or spontaneously. A weak signal is emitted by the inner ear into the environment (external auditory canal), from where it can be recorded with an OAE measuring apparatus (Kemp D. T., 1978),

3. examination of evoked auditory potentials. BERA, ERA, CERA - involves the action of a specific stimulus with a voltage of $0.5 \mathrm{mV}$ to $100 \mathrm{mV}$ on sensory receptors, triggering bioelectrical activity (evoked potential) recorded in the appropriate area of the cerebral cortex, registered with electrodes placed on the scalp, which make it possible to determine place of hearing damage. (Kemp D. T., 1980)

\section{RESEARCH METHODOLOGY}

The subject of the research as part of the hearing screening campaign conducted by the Silesian University of Technology covered employees of the Silesian and Małopolska hard coal mines who underwent hearing screening at the Mobile Center for Hearing Diagnosis - the so-called Radio bus and total audiometry consisting in determining air and bone conduction in specialized hearing diagnostics points cooperating with the Silesian University of Technology, the company ACSłuchmed Sp. z o. o. from Lublin.

Prior to commencing the study, employees were also asked to complete an anonymous questionnaire regarding working conditions, exposure to noise and the discomfort they may experience in connection with work in excessive noise. In total, 3,265 active and former employees from 37 hard coal mines, 
currently operating as independent mines and combined mines or in liquidation, took part in the action. No occupational disease related to hearing loss has been found in the miners examined so far. The aim of the study was to identify the risks associated with the occurrence of noise in their daily professional, socio-cultural life and to determine the effects of its impact on the hearing organ. The research allowed:

a) identifying the main sources of noise to which miners were or are exposed during work,

b) determination on the basis of surveys of activities performed by miners, which may be accompanied by excessive noise,

c) determining the approximate degree of hearing impairment among the miners surveyed.

Miners' hearing screening tests were conducted for 4 months from August 19 to November 30, 2019. by specialized diagnostic teams that included a hearing care professional from ACSłuchmed Sp. z o. o and a driver of the Mobile Diagnostic Center. Miners had at their disposal two Peugeot Boxer cars (Fig. 2) equipped with a silence cabin and AD 226 audiometer from Interacoustics with appropriate permits and certificates (Fig. 3).
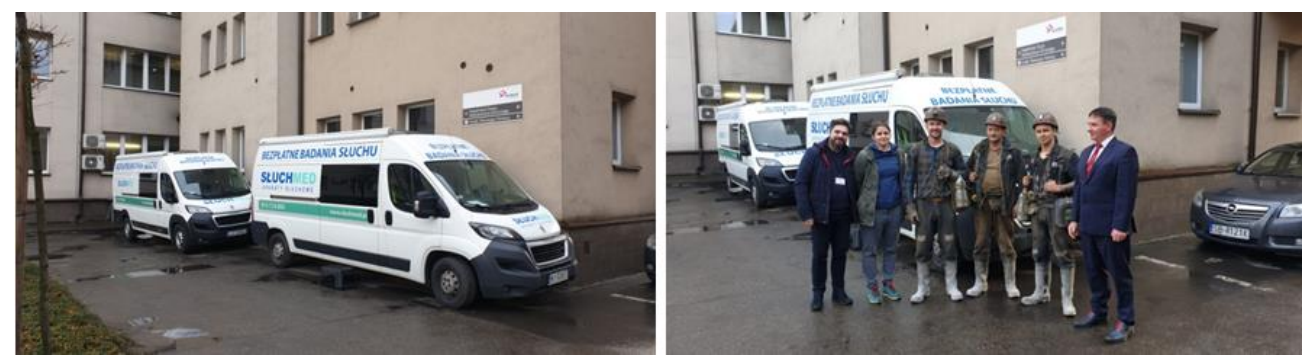

Fig. 2 Hearing screening tests at ZG "Brzeszcze"

Source: Own source

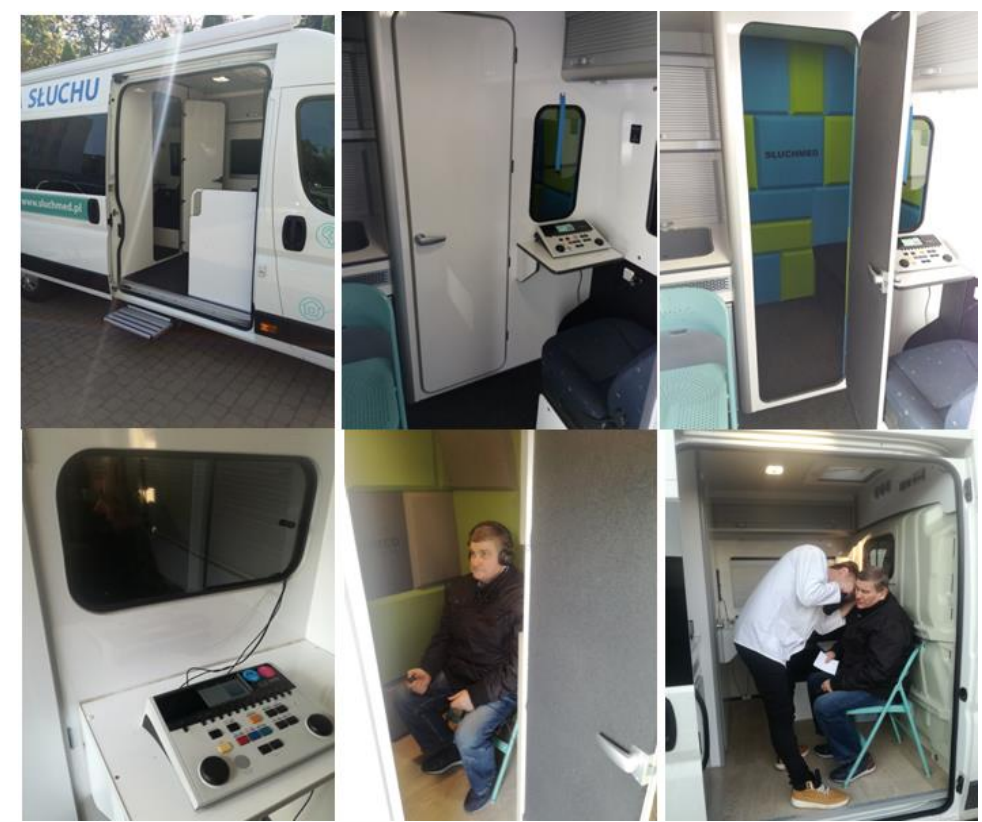

Source: Own source

Fig. 3 Equipment of the screening bus 
The research was carried out according to a predetermined schedule in which hard coal mines and mining plants were divided into five research groups, due to their location and functionality. Extramural students of the GIG of the Silesian University of Technology working every day in hard coal mines were also selected for the sixth group of respondents. The tests were carried out from $10 \mathrm{am}$ to $4 \mathrm{pm}$ in buses, which, with the consent of the management of the mines and mining plants, stood directly in front of the mine entrance or in the parking lot of the mining clinic. Participation in hearing screening was anonymous, voluntary and free. The only conditions for participating in the study were work at the mine and completing an anonymous survey regarding employee contact with noise.

The scope of hearing screening included:

- Initial interview with the patient - the purpose of which was to familiarize himself with the personal data of the examined person such as: date of birth or telephone number enabling subsequent contact, as well as with the needs, fears and expectations of the patient.

- medical history enabling familiarization with the patient's medical history. Such information is important for a hearing diagnostician because additional patient illnesses may periodically change his hearing and affect the result of a hearing test.

- environmental interview - the purpose of which was to obtain information on what the patient is currently doing. Is he exposed to high levels of noise. What kind of work he does professionally and how he spends his free time (yearly concerts, discos, sporting events) and in which situations the patient has the greatest problems with hearing and understanding speech.

- sight-glass examination of the patient's ears - whose purpose was to check the condition of the external auditory canal and tympanic membrane before proceeding with audiological tests. During the tests, a cork was found preventing diagnosis in 216 miners who were directed to clean the ear canal to an ENT specialist.

- hearing screening using a silence booth and an audiometer - consisted in giving audiometric headphones in a muted room a sound of different frequencies and signaling the patient to recognize sound (hearing threshold). By pressing the button the patient signaled the moment when he starts to hear the tones given to him, the frequency of which is successively increased. The aim of the study was to extract from a given population those people who have specific medical conditions, e.g. hearing impairment. If the results of the screening indicated hearing loss, the prosthetist informed the patient what steps should be taken to prevent the worsening of hearing loss and referred the patient to comprehensive tests to the nearest place of residence of the ENT office or hearing prosthetics company ACSłuchmed Sp. zo. o.

- total audiometry - was performed in one of the prosthetic offices of the ACSłuchmed Sp. z o. O., to which patients with suspected hearing 
impairment or diagnosed hearing impairment diagnosed as a result of screening were referred. The tests carried out in the office were to verify the degree of hearing impairment in the patient based on for example air and bone audiometry.

\section{HEARING SCREENING RESULTS}

In total, 3265 people took part in the screening study. Most of them were professionally active men, ie. $89.6 \%$. The examined women $11.4 \%$ are mainly employees of the coal processing plant and the energy-mechanical department servicing the main mine fan stations. The research covered employees from each age group, whose average seniority in mining was around 18 years. This condition is undoubtedly caused by the generational change that took place in connection with the mining reform in 2015 and the departure for mining or retirement of older employees. The largest group of respondents $32.4 \%$ were employees between 31-40 years old, the smallest $5.2 \%$ employees over 50 years old.

The largest group among the respondents were employees employed in such positions as a miner - $26.6 \%$ of respondents, supervisors of various departments $-11 \%$ of respondents, processing employees $-8.1 \%$, rescuers $8.0 \%$ and locksmiths $7.7 \%$ representatives of virtually all mining departments, and their number in individual groups correlates with the actual level of employment in individual departments. For people associated with the industry, it is no secret that employment in mining and exploitation and preparation departments is the largest, followed by energy and mechanical departments in terms of numbers. Hearing screening and total audiometry studies, however, have shown that it is not these professional groups that are most affected by the effects of excessive exposure to noise in the mine. Most often, hearing injuries and impairment of the organ occur among blast shots. Nearly half $(46.0 \%)$ of them had hearing loss or deafness. A similar phenomenon of high intensity occurs at the position of plumbers operating high pressure pumps, compressor sets and main drainage systems (41.2\%). A significant risk of hearing impairment is also recorded in employees associated with the operation of belt conveyors both in underground conditions and on the surface in a coal processing plant, where the increase in noise emissions is additionally intensified by ring crushers, vortex mixers or enrichers. The percentage share of respondents according to positions is presented in Table 3. This table also shows the percentage of people who were diagnosed with final cases of hearing impairment at individual work places.

Employees of the blasting, energy-mechanical and mechanical coal processing departments also belong to those mine departments where the greatest number of people with hearing impairments are encountered (Table 4), so presumably the emission of industrial noise in these departments is significant and exceeds the applicable hygiene standards. In order to verify this statement, actions were taken to carry out actual measurements of the industrial noise intensity in the Blasting Techniques Department, during the execution of technological 
processes in underground conditions. The research was carried out in mining excavations of three hard coal mines.

Table 3 Identified hearing loss at individual workstations

\begin{tabular}{|r|l|c|c|}
\hline \multicolumn{1}{|c|}{ No. } & \multicolumn{1}{|c|}{ Position } & $\begin{array}{c}\text { Percentage } \\
\text { of respondents } \\
\text { surveyed by position }\end{array}$ & $\begin{array}{c}\text { Hearing impairment } \\
\text { in the given group }\end{array}$ \\
\hline 1. & Miner & $26.6 \%$ & $13.2 \%$ \\
\hline 2. & Combine Driver & $1.6 \%$ & $21.2 \%$ \\
\hline 3. & Conveyor service & $5.1 \%$ & $36.9 \%$ \\
\hline 4. & Driller & $2.1 \%$ & $4.3 \%$ \\
\hline 5. & Paramedic & $8.0 \%$ & $11.2 \%$ \\
\hline 6. & Methane oprrator & $2.3 \%$ & $8.1 \%$ \\
\hline 7. & Filler & $1.6 \%$ & $23.1 \%$ \\
\hline 8. & Conservator & $2.4 \%$ & $23.1 \%$ \\
\hline 9. & Driver & $1.3 \%$ & $24.4 \%$ \\
\hline 10. & Locksmith & $7.7 \%$ & $25.4 \%$ \\
\hline 11. & Plumber & $3.1 \%$ & $41.2 \%$ \\
\hline 12. & Carpenter & $2.5 \%$ & $34.1 \%$ \\
\hline 13. & Linie operator & $2.1 \%$ & $30.4 \%$ \\
\hline 14. & Signaller & $2.6 \%$ & $18.8 \%$ \\
\hline 15. & Electrician & $6.0 \%$ & $19.5 \%$ \\
\hline 16. & Processing worker & $8.1 \%$ & $35.0 \%$ \\
\hline 17. & Geologist & $0.5 \%$ & $0.0 \%$ \\
\hline 18. & Blasting worker & $2.7 \%$ & $46.0 \%$ \\
\hline 19. & Power engineer & $1.9 \%$ & $12.9 \%$ \\
\hline 20. & Lab worker & $0.5 \%$ & $0.0 \%$ \\
\hline 21. & Inspector & $0.3 \%$ & $11.1 \%$ \\
\hline 22. & Supervisor & $11.0 \%$ & $18.6 \%$ \\
\hline
\end{tabular}

Table 4 Identified hearing loss among employees in individual departments.

\begin{tabular}{|r|l|c|c|}
\hline No. & \multicolumn{1}{|c|}{ Position } & $\begin{array}{c}\text { Percentage } \\
\text { of respondents } \\
\text { by department }\end{array}$ & $\begin{array}{c}\text { Hearing disorders } \\
\text { found in each } \\
\text { ward }\end{array}$ \\
\hline 1. & Mining department & $37.1 \%$ & $17.5 \%$ \\
\hline 2. & Mining department & $2.4 \%$ & $3.8 \%$ \\
\hline 3. & Mining department & $16.2 \%$ & $13.4 \%$ \\
\hline 4. & $\begin{array}{l}\text { Power engineering } \\
\text { department }\end{array}$ & $28.0 \%$ & $25.7 \%$ \\
\hline 5. & $\begin{array}{l}\text { Mechanical processing } \\
\text { department }\end{array}$ & $9.1 \%$ & $34.0 \%$ \\
\hline 6. & $\begin{array}{l}\text { Measure and geological } \\
\text { department }\end{array}$ & $0.8 \%$ & $0.0 \%$ \\
\hline 7. & $\begin{array}{l}\text { Department of blasting } \\
\text { techniques }\end{array}$ & $3.2 \%$ & $47.6 \%$ \\
\hline 8. & Energy department & $2.1 \%$ & $14.5 \%$ \\
\hline 9. & $\begin{array}{l}\text { Environmental protection } \\
\text { department }\end{array}$ & $0.7 \%$ & $0.0 \%$ \\
\hline 10. & $\begin{array}{l}\text { Department of material } \\
\text { management }\end{array}$ & $0.4 \%$ & $7.7 \%$ \\
\hline
\end{tabular}

\section{NOISE THREAT IN THE BLASTING TECHNOLOGY DEPARTMENT OF HARD COAL MINES}

The mechanization of mineral deposit mining commonly used in underground mining plants has not eliminated the use of blasting methods. The amount of their usage is constantly maintained still at a high level, and in many cases 
the use of blasting materials at a hard coal mine is the only way to carry out preparatory work in stone excavations or preventive work carried out in coal seams at risk of rock bursts.

The management of blasting equipment is responsible for the management of blasting methods, blasting equipment as well as supervision and conducting blasting works, especially in methane fields, fields at risk of gas and rock outbursts, or in the area of bursting decks. The core of this department is blasting instructor and blasting worker who every day drill several dozen small-diameter holes in the excavation outline in accordance with the prepared shot metric using manual or stationary pneumatic and electric tools with high powers. Fig. 4.

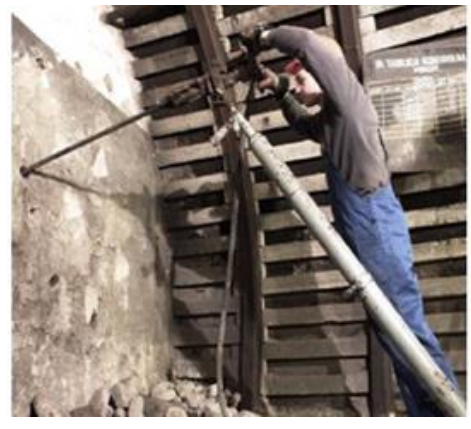

Source: (Zając C., 2020 http://www.czek.eu/)

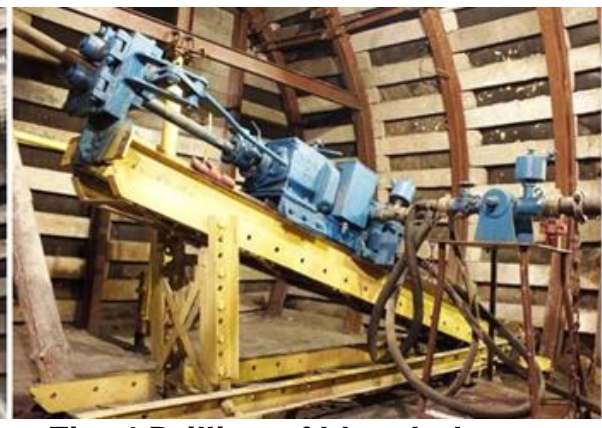

Fig. 4 Drilling of blast holes

Then they load explosives and the stick. After completing these activities, explosives are fired, detonation and formation of rock masses, or in the case of preventive measures, stress relief inside the rock mass. During the performance of these activities, employees are accompanied by noise of significant intensity, which it was decided to measure.

\section{MEASUREMENT METHODOLOGY AND APPARATUS USED IN THEM}

Measurements of sound intensity were made during drilling of stone and stonecoal excavations with the use of explosives and during preventive works related to shock and torpedo blastings in the area of walls threatened with rock bursts. The measurements were carried out in accordance with the provisions of the PN-EN ISO 9612: 2011 and PN-N-01307:1994 standards (PN, 2014, PN, 1994). The tests measured sound intensity $L_{\text {Aeq }}$ emitted by hand tools and devices as well as maximum sound level $A-L_{A m a x}$, peak sound level $C-L_{\text {cpeak }}$ during the detonation of explosives. The essence of the measurements was to determine the noise that arises during the performance of individual technological processes.

To determine the sound level emitted by manual and stationary pneumatic and electric tools, and during the detonation of explosives, the integrating sound level meter DLM -101 from P.P.U.H Sonopan Sp. z. o. o. This meter has a first accuracy class and meets the requirements of PN-EN 61672-1:2014 (PN, 2014). It is a meter enabling measurement of sound intensity both at workplaces and in the environment. It allows you to work at temperatures from $-10^{\circ} \mathrm{C}$ to $50^{\circ} \mathrm{C}$ 
and up to $90 \%$ humidity, without measurement distortion results. The measuring range of the meter is $24-135 \mathrm{dBA}$ and $45-137 \mathrm{dBC}$.

The basis for assessing the noise level were the results of three measurements at each test stand during individual technological processes. The average sound levels LAeqśr were determined from the relationships described in the previously cited standards.

\section{MEASUREMENT RESULTS OF SOUND INTENSITY EMITTED BY INDIVIDUAL TOOLS AND DEVICES AND DURING THE DETONATION OF EXPLOSIVES}

Averaged results of tests carried out in the Department of Blasting Technology of three hard coal mines during works related to boring stone and coal-coal mining work with the use of explosives and during preventive works related to shock and torpedo blastings in the area of walls threatened with rock bursts are listed in Tables 5 to 7 . Table 5 shows, for example, the results of individual measurements of sound intensity $L_{\text {Aeq, }} L_{\text {Aeqsir, }} L_{\text {Cpeak }}$ and $L_{\text {Amax }}$ while drilling holes with a manual electric drill type RE61.

Table 5 Results of sound intensity measurements when drilling holes with a drill

\begin{tabular}{|c|c|c|c|c|c|}
\hline $\begin{array}{c}\text { Hand tools, } \\
\text { device }\end{array}$ & \multirow{2}{*}{$\begin{array}{c}\text { Measured } \\
\text { parameter }\end{array}$} & \multicolumn{3}{|c|}{$\begin{array}{c}\text { Results of } \\
\text { measurements [dB] }\end{array}$} & \multirow{2}{*}{$\begin{array}{c}\text { Basis for noise } \\
\text { assessment [dB] }\end{array}$} \\
\cline { 3 - 5 } & & $\mathbf{1}$ & $\mathbf{2}$ & $\mathbf{3}$ & \\
\hline Power drill & LAeq & 86.4 & 85.7 & 88.3 & 86.9 \\
\cline { 2 - 5 } GMP-RE61 & LAmax & 93.3 & 92.4 & 95.8 & 95.8 \\
\cline { 2 - 5 } & LCpeak & 100.1 & 99.6 & 102.4 & 102.4 \\
\hline
\end{tabular}

Table 6 presents the average collective results obtained from the tests, the intensity of sound emitted by individual tools and devices operated during drilling of blast holes by employees of the Blasting Technology Department in three mines. In this table, in addition to the average sound level $A$, maximum sound level $A$, peak sound level $C$, the values for exceeding the hygiene standards for each machine and device are also given. These data show that employees of the Blasting Technology Department are constantly exposed to a high level of noise emissions in mining excavations, especially when using pneumatic tools that emit noise exceeding the allowable norms by several dozen to several hundred times.

Table 7 also presents collective results of sound intensity measurements during blasting operations at the blasting station. The maximum and peak sound level values were recorded when firing explosives. The highest sound level was recorded during blasting operations in stone headings with dynamite-based rock explosives. 
Table 6 Results of measurements of sound intensity emitted by individual tools and devices during drilling of blast holes

\begin{tabular}{|c|c|c|c|c|c|}
\hline No. & $\begin{array}{l}\text { Hand } \\
\text { tools, } \\
\text { Devices }\end{array}$ & $\begin{array}{c}\text { Average sound } \\
\text { level } \\
L_{\text {Aeqsr }}[\mathrm{dB}]\end{array}$ & $\begin{array}{c}\text { Maximum sound } \\
\text { level } \\
\mathrm{L}_{\text {Amax }}[\mathrm{dB}]\end{array}$ & $\begin{array}{l}\text { Peak sound } \\
\text { level } C \\
L_{\text {Cpeak }}[\mathrm{dB}]\end{array}$ & $\begin{array}{l}\text { Exceeding } \\
\text { NDN } \\
\text { [dB] }\end{array}$ \\
\hline \multicolumn{6}{|c|}{ Power drill } \\
\hline 1. & ER - 61 & 86.9 & 95.8 & 102.4 & 1.5 \\
\hline 2. & ER - 62 & 88.4 & 96.2 & 103.2 & 2.2 \\
\hline 3. & ER - 62U & 90.2 & 101.4 & 109.8 & 3.3 \\
\hline \multicolumn{6}{|c|}{ Hydraulic hand drill } \\
\hline 4. & WHG-100 & 83.6 & 89.1 & 93.3 & 0.7 \\
\hline \multicolumn{6}{|c|}{ Impact and pneumatic drills } \\
\hline 5. & YT24/7655D & 102.4 & 110.1 & 121.7 & 55.0 \\
\hline 6. & WU29 & 108.7 & 114.6 & 131.2 & 234.4 \\
\hline 7. & WUP-22 & 105.6 & 112.2 & 128.6 & 114.8 \\
\hline \multicolumn{6}{|c|}{ Pneumatic drills } \\
\hline 8. & Y19A & 96.4 & 101.3 & 110.8 & 13.8 \\
\hline 9. & Y26 & 104.1 & 119.6 & 126.4 & 81.3 \\
\hline 11. & WOK 50 & 91.2 & 96.1 & 104.2 & 4.2 \\
\hline 12. & WOK 80 & 95.0 & 99.2 & 111.6 & 10.0 \\
\hline 13. & WOK 100 & 99.6 & 102.4 & 116.2 & 28.8 \\
\hline 14. & WOK 140 & 102.1 & 113.4 & 122.6 & 51.3 \\
\hline 15. & PWR II & 96.3 & 98.2 & 112.7 & 13.5 \\
\hline 16. & PWR - 5UC & 110.6 & 118.6 & 130.1 & 363.1 \\
\hline 17. & PWR - 8T & 109.3 & 113.6 & 124.1 & 269.2 \\
\hline \multicolumn{6}{|c|}{ Pneumatic drilling hammer } \\
\hline 18. & $\mathrm{~B} 5 \mathrm{H}$ & 92.1 & 99.4 & 105.3 & 5.1 \\
\hline 19. & $\mathrm{~B} 8 \mathrm{H}$ & 100.7 & 111.3 & 120.6 & 37.2 \\
\hline \multicolumn{6}{|c|}{ Hydraulic drilling rig } \\
\hline 20. & HWK - 75 & 87.6 & 91.6 & 99.2 & 1.8 \\
\hline 21. & MDR - 03 & 84.6 & 90.3 & 95.5 & 0.9 \\
\hline 22. & MDR - 06A & 85.7 & 94.1 & 97.3 & 1.2 \\
\hline 23. & WD - 06H & 80.4 & 86.3 & 92.6 & 0.3 \\
\hline 24. & WD - 02EA & 82.1 & 86.4 & 93.1 & 0.5 \\
\hline 25. & WD - 02EA/P & 89.6 & 96.3 & 100.4 & 2.9 \\
\hline \multicolumn{6}{|c|}{ Pneumatic drilling rig } \\
\hline 26. & PWK -75 & 105.2 & 118.6 & 132.3 & 104.7 \\
\hline
\end{tabular}

Table 7 Results of sound intensity measurements during blasting operations at the blasting stand

\begin{tabular}{|c|c|c|c|c|c|}
\hline \multirow[t]{2}{*}{ No. } & \multirow{2}{*}{$\begin{array}{c}\text { Type } \\
\text { of explosive }\end{array}$} & \multicolumn{2}{|c|}{ Maximum sound level $L_{A m a x}[\mathrm{~dB}]$} & \multicolumn{2}{|c|}{ Peak sound level CLcpeak [dB] } \\
\hline & & Measured & Approximate & Measured & Approximate \\
\hline \multirow{3}{*}{1.} & \multirow{3}{*}{$\begin{array}{l}\text { Special } \\
\text { methanite }\end{array}$} & 104.8 & \multirow{3}{*}{105.5} & 126.7 & \multirow{3}{*}{127.7} \\
\hline & & 106.3 & & 129.2 & \\
\hline & & 105.4 & & 127.3 & \\
\hline \multirow{3}{*}{2.} & \multirow{3}{*}{ Emulnit PM } & 113.4 & \multirow{3}{*}{115.0} & 133.9 & \multirow{3}{*}{131.8} \\
\hline & & 115.6 & & 134.3 & \\
\hline & & 116.1 & & 135.6 & \\
\hline \multirow{3}{*}{3.} & \multirow{3}{*}{ Ammonite } & 116.7 & \multirow{3}{*}{117.8} & 134.8 & \multirow{3}{*}{136.0} \\
\hline & & 117.5 & & 136.4 & \\
\hline & & 119.1 & & 136.9 & \\
\hline \multirow{3}{*}{4.} & \multirow{3}{*}{ Emulnit 2} & 116.9 & \multirow{3}{*}{117.3} & 134.1 & \multirow{3}{*}{134.5} \\
\hline & & 117.6 & & 134.9 & \\
\hline & & 117.4 & & 134.4 & \\
\hline \multirow{3}{*}{5.} & \multirow{3}{*}{ Paladin } & 118.6 & \multirow{3}{*}{119.6} & 136.8 & \multirow{3}{*}{$>137.0$} \\
\hline & & 119.3 & & 1370 & \\
\hline & & 120.9 & & $>137.0$ & \\
\hline \multirow{3}{*}{6.} & \multirow{3}{*}{ Ergodyn } & 120.2 & \multirow{3}{*}{121.2} & $>137.0$ & \multirow{3}{*}{$>137.0$} \\
\hline & & 121.6 & & (meter & \\
\hline & & 121.9 & & $\begin{array}{c}\text { range } \\
\text { exceeded) }\end{array}$ & \\
\hline
\end{tabular}




\section{SURVEYS}

Surveys conducted among employees of the Blasting Techniques Department were part of the miner's hearing screening program conducted in 2019 by the Silesian University of Technology and ACSłuchmed Sp. z o. o. The research was carried out in order to verify the work environment and life of miners, and to determine the risks associated with noise that accompany them in professional work and in everyday life.

87 blasting departments of each of 37 mines participated in the study. Due to the elitism of this profession, this is a large random sample. Hearing changes caused by exposure to excessive noise were diagnosed in as many as 40 people. $91.6 \%$ of the surveyed were professionally active employees, the remaining $8.4 \%$ were pensioners. The average age of respondents is 41 years, which proves the employees' long experience and experience. To the questions related to the occurrence of noise at the workplace, the respondents emphasized ( $96.1 \%$ of respondents) that it accompanies them every day during their work and on average they are exposed to it from 4 to 6 hours $(78.4 \%$ of respondents), although among the shots there are also such employees for which the exposure time to noise exceeds 6 hours (19.4\% of respondents). Employees know the noise level at their workplaces is very high $(91.1 \%$ of respondents) especially when using pneumatic tools and devices, but they often use them because the efficiency of their use is much greater than that of electrical tools and devices or hydraulics. $76.4 \%$ of respondents emphasize that they constantly use personal protection equipment against noise $-54.1 \%$ in the form of earplugs, $22.3 \%$ use earmuffs. Unfortunately, as much as $23.6 \%$ of respondents also admit that although the employer equips them with personal protective equipment, they often do not use them because they interfere with recognizing the number of detonated explosives or changes occurring in the rock mass during work. Undoubtedly, the weak point of the work performed by employees of the Blasting Technology Department is the fact that collective protection measures cannot be applied to their work. In the matter of health changes caused by work in excessive noise, $28.3 \%$ of respondents perceived hearing impairment manifested by persistent ringing and tinnitus, and the need to turn up the radio and television receivers. However, they did not consult these changes with the ENT specialist. The rest of the employees diagnosed with changes in the hearing organs, even cases of advanced deafness, were not aware of this. Some of the respondents explained the process of hearing loss to themselves by the progressing aging of the body. Unfortunately, the awareness of miners in the aspect of health changes that occur in their body in connection with their work is low, and they are reluctant to see doctors.

\section{SUMMARY}

Industrial noise is a common phenomenon that occurs in the production process of any hard coal mine. As shown by the results of screening among 3265 people and total audiometry in 281 miners causes significant health changes in $20.9 \%$ of miners tested. 
Among 113 of the examined people, a significant (over $40 \%$ ) hearing loss was identified, which qualified employees to apply for an occupational disease benefit, despite the fact that they had never had such problems before. The department in which the most frequently diagnosed cases of hearing impairment in relation to the number of employees is the Department of Blasting Technology, and the workplace is a blasting station. As the measurement results of sound intensity tests showed during works related to boring stone and stone-coal excavations with the use of explosives and during preventive works related to shock and torpedo blastings in the area of walls threatened with bumps, the level of noise generated by machines and devices at blasting stations throughout the day is very high. Employees are aware of this and mostly use personal protection equipment against noise, but the solutions used are not very effective due to the nature of the work and the inability to apply collective protection measures. Due to the deterioration of hearing among people employed at the mine, there is a justified need to conduct further research on the possibility of introducing an industrial noise monitoring system in mining and introducing new hearing protectors that can improve the level of occupational safety.

\section{REFERENCES}

Eurostat, Work and health in the EU: a statistical portrait, 2014

EU - OSHA - European Agency for Safety and Health at Work, Data to describe the link between OSH and employability, 2012.

Koradecka D. [ed.]: Handbook of occupational safety and health. CRC Press, Taylor and Francis Group, Boca Raton, London, New York 2010

SH Lim, V Anantharaman, WS. Teo, PP Goh and others. Comparison of treatment of supraventricular tachycardia by Valsalva maneuver and carotid sinus massage. „Ann Emerg Med”. 31 (1), pp. 30-5, Jan 1998.

R. Nagappan, S. Arora, C. Winter. Potential dangers of the Valsalva maneuver and adenosine in paroxysmal supraventricular tachycardia-beware preexcitation. „Crit Care Resusc". 4 (2), pp. 107-11, Jun 2002.

Kozubski W., Liberski P. (ed.). Neurology. A textbook for medical students. Warsaw: PZWL Medical Publishing, 2006, pp. 61.

Thijs , P.Leffers , Sensitivity and specificity of Rinne tuning fork test., „BMJ: British Medical Journal", 298 (6668), 1989, pp. 255,

Śliwińska-Kowalska M., Bochnia M., Obrębowski A.: Clinical audiology. Lodz: Mediton Publishing House, 2005.

Kemp D. T. Stimulated acoustic emission from within the human auditory system. J Acoust Soc Am 1978; 64: 1386-1391

Kemp D. T. Towards model for the origin of cochlear echoes. Hear Res 1980; 2: 533548.

Hare. C. Teaching materials for miners. 2020, http://www.czek.eu/

Institute of Occupational Medicine in Łódź. Occupational hearing loss. http://www.programyzdrowotne.pl/, 2020

Department of Working Conditions of the State Mining Authority. Assessment of the state of work safety, mine rescue and universal safety in connection with mining and geological activities in 2018. WUG. Katowice 2019. www.wug.gov.pl

PN-EN ISO 9612:2011 Acoustics - Determination of occupational noise exposure Technical method.

PN-N-01307:1994 Noise - Permissible noise values in the work environment Requirements for performing measurements. 
PN-EN 61672-1:2014 Electroacoustics. Sound level meters. Part 1: Requirements.

\begin{abstract}
.
The publication presents partial results of hearing screening tests conducted in 2019 among employees of 37 hard coal mines located in the Śląskie and Małopolskie voivodships. The tests were carried out in different cities of both voivodships using the Mobile Hearing Diagnosis Center, which parked near the selected mine and specialized hearing diagnostics points of the ACSłuchmed Sp. z o. o. from Lublin. At the diagnostic points, detailed total audiometry tests were conducted on people diagnosed with hearing disorders as part of screening tests. The obtained results allowed to identify branches and workplaces with the highest risk of noise hazard in mines. The presented publication shows the results of noise measurement during blasting works and the results of anonymous surveys conducted among employees of the Department of Blasting Technology of hard coal mines. The survey concerned the subjective feelings of employees regarding noise levels at the workplace and its impact on their well-being and state of health. In the publication summary, the author draws attention to the need to take measures to constantly control the noise level at the workplace and introduce solutions that will enable its reduction and allow for better protection of employees against its damaging consequences.
\end{abstract}

Keywords: Blasting works, Hearing loss, hearing test, noise, miner 